\title{
Noninvasive ventilation duration as an outcome predictor in acute exacerbation of COPD and respiratory failure: The saga continues
}

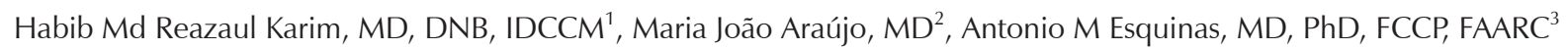

HMR Karim, MJ Araújo, AM Esquinas. Noninvasive ventilation duration as an outcome predictor in acute exacerbation of COPD and respiratory failure: The saga continues. Can J Respir Ther 2021;57:147. doi: 10.29390/cjrt-2021-069.

Key Words: COPD; acute hypercapnic respiratory failure; noninvasive ventilation; outcome

\section{Dear Editor,}

We applaud the study by Ghazala et al. [1], where the authors analyzed predictors of clinical outcomes in acute exacerbation of chronic obstructive pulmonary disease (COPD) requiring noninvasive ventilation (NIV). Although the study is retrospective in nature, the use of multivariate regression analysis is pragmatic. Understanding predictive models is a hot topic; the study finding was thought provoking and, and we consider some key aspects for discussion.

The APACHE-III (Acute Physiology and Chronic Health Evaluation) is an acceptable and predictable factor; however, body mass index (BMI) as an independent predictor needs more study [2]. NIV settings and titration of positive airway pressures used in an obese patient are crucial, as these patients often require higher pressures to overcome the obstruction [3]. The data on sleep-disordered breathing; worsening clinical condition; reasons for delaying or prolong $\mathrm{NIV}, \mathrm{PaO}_{2}$ (partial pressure of oxygen in arterial blood), and/or $\mathrm{SpO}_{2}$ (peripheral oxygen saturation); and $\mathrm{pH}$ levels would be informative [4].

Furthermore, adherence to predefined NIV failure criteria or criteria to start invasive mechanical ventilation (IMV) following NIV failure is crucial as it can deter possible practice variations, impacting the decision of IMV and thereby the outcome. Accordingly, the authors' finding that NIV duration did not predict the clinical outcome, even in failed patients, might be erroneous. Additionally, a dedicated team caring for NIV patients impacts the clinical outcomes [5].

Therefore, in our assessment, discarding the impact of NIV duration and accepting the BMI as a predictor of worse clinical outcomes appears premature on the background of current evidence. We would welcome the authors' opinions on these points.

Habib Md Reazaul Karim Maria João Araújo Antonio M Esquinas

\section{REFERENCES}

1. Ghazala L, Hatipoğlu U, Devnani T, et al. duration of noninvasive ventilation is not a predictor of clinical outcomes in patients with acute exacerbation of COPD and respiratory failure. Can J Respir Ther 2021;57:113-18. doi: 10.29390/cjrt-2021-021.

2. Steriade AT, Johari S, Sargarovschi N, et al. Predictors of outcome of noninvasive ventilation in severe COPD exacerbation. BMC Pulm Med 2019;19(1):131. doi: 10.1186/s12890-019-0892-9.

3. Kushida CA, Chediak A, Berry RB, et al. Positive Airway Pressure Titration Task Force; American Academy of Sleep Medicine. Clinical guidelines for the manual titration of positive airway pressure in patients with obstructive sleep apnea. J Clin Sleep Med 2008;4(2):157-71. doi: $10.5664 / \mathrm{jcsm} .27133$.

4. Osadnik CR, Tee VS, Carson-Chahhoud KV, et al. Noninvasive ventilation for the management of acute hypercapnic respiratory failure due to exacerbation of chronic obstructive pulmonary disease. Cochrane Database Syst Rev 2017;7(7):CD004104. doi: 10.1002/14651858. CD004104.pub4.

5. Vaudan S, Ratano D, Beuret P, et al. Impact of a dedicated noninvasive ventilation team on intubation and mortality rates in severe COPD exacerbations. Respir Care 2015;60(10):1404-8. doi: 10.4187/ respcare.03844.

\footnotetext{
${ }^{1}$ Department of Anaesthesiology and Critical Care, All India Institute of Medical Sciences, Raipur, India

${ }^{2}$ Pulmonary Department, Hospital de Braga, Braga, Portugal

${ }^{3}$ Intensive Care Unit, Hospital Morales Meseguer, Murcia, Spai

Correspondence: Habib Md Reazaul Karim, Faculty Room A001, Block A, All India Institute of Medical Sciences, Raipur. India. PIN 492099.

Tel: +919612372585. E-mail: drhabibkarim@gmail.com
} 